\title{
An Improved Method to Obtain a Soluble Nuclear Fraction from Embryonic Brain Tissue
}

\author{
Sebastián Giusti · María Eugenia Bogetti · \\ Antonela Bonafina $\cdot$ Sara Fiszer de Plazas
}

Accepted: 7 May 2009/Published online: 22 May 2009

(C) Springer Science+Business Media, LLC 2009

\begin{abstract}
This paper describes modifications of the standard methods for obtaining a soluble nuclear fraction from embryonic brain tissue. The main improvements are: (1) the inclusion of a low speed centrifugation step to prevent the appearance of high density contaminants, (2) a sucrose density gradient to remove perinuclear mitochondria and ER membranes and (3) a protein extraction approach which significantly enhances protein yield. To demonstrate the effectiveness of the method, pellets were analyzed by light and electron microscopy and purity of the soluble extracts was immunologically tested. Finally, to illustrate the applicability of this approach, the induction of the transcription factor HIF-1 (hypoxia-inducible factor-1) was assessed by Western blot using soluble nuclear fractions and by immuno-electron microscopy using purified nuclear fractions, both obtained from the optic lobes of chick embryos. In conclusion, the procedure presently described appears to be reliable and convenient for obtaining a pure soluble nuclear fraction from a discrete amount of embryonic brain tissue.
\end{abstract}

Keywords Subcellular fractionation .

Soluble nuclear fraction - Embryonic brain tissue . Transcription factors - Western blot

S. Giusti · M. E. Bogetti · A. Bonafina · S. Fiszer de Plazas $(\square)$ Institute of Cell Biology and Neuroscience "Prof. E De Robertis", School of Medicine, University of Buenos Aires, Paraguay 2155, 1121 Buenos Aires, Argentina

e-mail: sfiszer@fmed.uba.ar

\section{Introduction}

Signaling to living cells by growth factors, hormones, transmitters and stress stimuli leads to a modulation of gene expression via several molecular mechanisms. Transcription factors integrate different signaling networks and are therefore at the center of the adaptive response of cells [1]. As a result, understanding cellular responses depends largely on the assessment of the intensity and kinetics of the activation of transcription factors. Both aspects can be determined by Western blotting, a simple and reliable experimental approach. In this context, the preparation of a soluble nuclear fraction (SNF) is often required as a first step.

Several problems arise when the source tissue is derived from embryonic brain structures. Embryos are too small to be perfused and despite extensive rinsing of the dissected material, crude nuclear pellets contain large amounts of red blood cells, fragments of capillaries, intact cells and other debris of relatively large size and high density. Besides, low density contaminants like endoplasmic reticulum (ER) fragments and mitochondria, are also found in the nuclear fraction. Together, these contaminants add variability to the results and contribute to mask subtle signals, especially when the inactive transcription factor is immunologically indistinguishable from the active form and is present in other subcellular compartment.

In order to solve these problems we developed a fractionation procedure based on consideration of a large number of reports concerning both the purification and protein extraction from nuclei. The purification of nuclei proposed here resembles the procedure first described by Blobel and Potter [2], but with major modifications. A low speed centrifugation step immediately after homogenization (and before nuclear pelleting) minimized the number 
of red blood cells and the amount of debris contamination. The next step in this isolation procedure was the sedimentation of nuclei through a sucrose solution with sufficient density to float the ER and mitochondria while pelleting the nuclei. During this procedure, as nuclei move down through the sucrose solution, the ER moves upward and is stripped from the nuclei without significantly affecting their integrity.

For extraction of nuclear proteins, we used a treatment with high salt and detergent combined with shearing through a syringe. This procedure fragments the DNA and releases the majority of proteins [3]. Importantly, we found that the addition of a low concentration of sodium dodecyl sulphate (SDS) as a complement of the classical Triton$\mathrm{X}-100$ significantly improved protein yield.

To demonstrate the effectiveness of the proposed method, morphology of the pellets was analyzed by light and electron microscopy, and purity of the soluble extracts was immunologically tested using subcellular specific markers.

Finally, to illustrate the applicability of this approach, the induction of the transcription factor HIF-1 (hypoxiainducible factor-1) was assessed by Western blot using SNFs and by immuno-electron microscopy using purified nuclear fractions (PNFs), both obtained from the optic lobes of chick embryos (bilateral mesencephalic structures involved in visual processing).

\section{Experimental Procedures}

Animals

White Leghorn fertile chicken (Gallus gallus domesticus) eggs were obtained from a local hatchery and incubated at $37^{\circ} \mathrm{C}$ and $60 \%$ relative humidity. They were sacrificed at embryonic day 12.

\section{Soluble Nuclear Fraction}

The complete procedure, outlined in Fig. 1, includes the isolation of nuclei and posterior nuclear protein extraction.

\section{Working Solutions}

Buffer A: $0.32 \mathrm{M}$ sucrose, $20 \mathrm{mM}$ Tris- $\mathrm{HCl}$ (pH 7.4), $1 \mathrm{mM}$ EDTA, $1 \mathrm{mM}$ EGTA, $1 \mathrm{mM}$ DTT, $75 \mu \mathrm{g} / \mathrm{ml}$ spermidine; phosphatase inhibitors: $50 \mathrm{mM} \mathrm{NaF}, 1 \mathrm{mM}$ $\mathrm{Na}_{3} \mathrm{VO}_{4}, 1 \mathrm{mM}$ ammonium molybdate; protease inhibitors: $1 \mu \mathrm{M}$ leupeptin, $1 \mu \mathrm{M}$ aprotinin, $1 \mu \mathrm{M}$ pepstatin $\mathrm{A}$ and $1 \mu \mathrm{M}$ PMSF. DTT, spermidine and protein inhibitors should be added just prior to use.
Buffer B: 1.6 M sucrose, $20 \mathrm{mM}$ Tris (pH 7.4), $5 \mathrm{mM}$ $\mathrm{MgCl}_{2}, 1 \mathrm{mM}$ DTT, $75 \mu \mathrm{g} / \mathrm{ml}$ spermidine and $1 \mu \mathrm{M}$ PMSF. DTT, spermidine and PMSF should be added just prior to use.

Buffer C: $0.32 \mathrm{M}$ sucrose, $20 \mathrm{mM}$ Tris- $\mathrm{HCl}$ (pH 7.4).

Buffer D: $20 \mathrm{mM}$ HEPES (pH 7.9), $0.5 \mathrm{M} \mathrm{NaCl}$, $1.5 \mathrm{mM} \mathrm{MgCl}_{2}, 0.2 \mathrm{mM}$ EDTA, $1 \% \mathrm{v} / \mathrm{v}$ Triton-X-100, $0.025 \% \mathrm{w} / \mathrm{v}$ SDS, $1 \mathrm{mM}$ DTT, $1 \mu \mathrm{M}$ PMSF and $20 \%$ glycerol. DTT and PMSF should be added just prior to use.

PBS: phosphate-buffered saline, $0.007 \mathrm{M} \mathrm{Na} \mathrm{HPO}_{4}$, $0.003 \mathrm{M} \mathrm{NaH}_{2} \mathrm{PO}_{4}, 1.3 \mathrm{M} \mathrm{NaCl}$ (pH 7.4).

Buffers can be stored at $4^{\circ} \mathrm{C}$ for 2 weeks.

\section{Isolation of Nuclei}

1. Chick embryos were sacrificed by decapitation and optic lobes were quickly removed and placed in icecold PBS.

2. Optic lobes from six embryos $(\sim 0.6 \mathrm{~g})$ were pooled and homogenized in buffer A $(1 / 10 \mathrm{w} / \mathrm{v})$ in a PotterElvehjem homogenizer.

3. The homogenate was centrifuged at $75 \mathrm{~g}(1,000 \mathrm{rpm}$ using a Sorvall SS-34 rotor) for $4 \mathrm{~min}$. Care should be taken to avoid disturbing the loose reddish pellet containing high density contaminants (HDC) while removing and saving the supernatant $\left(\mathrm{S}_{1}\right)$.

4. $\mathrm{S}_{1}$ was centrifuged at $900 \mathrm{~g}(2,750 \mathrm{rpm}$ using a Sorvall SS-34 rotor) for $10 \mathrm{~min}$. Following centrifugation, the new supernatant $\mathrm{S}_{2}$ was removed and the pellet $\left(\mathrm{P}_{1}\right)$ was washed by rapid rehomogenization in buffer $\mathrm{A}$ and centrifuged again. The new pellet, the nuclear enriched fraction (NEF), is whitish and more compact than HDC.

5. NEF was resuspended in $6 \mathrm{ml}(3 \mathrm{ml}$ of buffer $\mathrm{A}$ and $3 \mathrm{ml}$ of buffer B) and homogenized with two strokes of the homogenizer. The final sucrose concentration of the solution is $\sim 1 \mathrm{M}$.

6. The resuspended NEF was layered onto a $6 \mathrm{ml}$ sucrose cushion of buffer B in a SW28 ultracentrifuge tube. Tubes should be completely filled during centrifugation to avoid collapsing. Buffer $\mathrm{C}$ is layered onto the sample to complete the volume of the tubes.

7. Samples were centrifuged at $80,000 \mathrm{~g}(24,500 \mathrm{rpm})$ in a Beckman SW28 rotor for 35 min. Following centrifugation a Pasteur pipette is used to remove a layer of whitish membranous material formed between the $1 \mathrm{M} / 1.6 \mathrm{M}$ density step. The remaining supernatant was poured off by rapidly inverting the tubes. Purified nuclei remain as a tight, opaque pellet at the bottom of the tubes $\left(\mathrm{P}_{2}\right)$.

8. $\mathrm{P}_{2}$ was resuspended in $0.5 \mathrm{ml}$ of buffer $\mathrm{A}$, placed in a 1.5-ml microcentrifuge tube, and pelleted by a quick spinning $(30 \mathrm{~s})$ in a microcentrifuge. This pellet 
Fig. 1 Schematic diagram illustrating the method described in this study to obtain a soluble nuclear fraction $(S N F)$ from embryonic brain tissue. Dashed line: modified version of the method to demonstrate the effect of the sucrose cushion step in the purity of the protein extract (see "Results").

$P$, pellet; $S$, supernatant; $H D C$, high density contaminants;

$N E F$, nuclear enriched fraction; $P N F$, purified nuclear fraction; $I F$, insoluble fraction; $I S N F$, impure soluble nuclear fraction

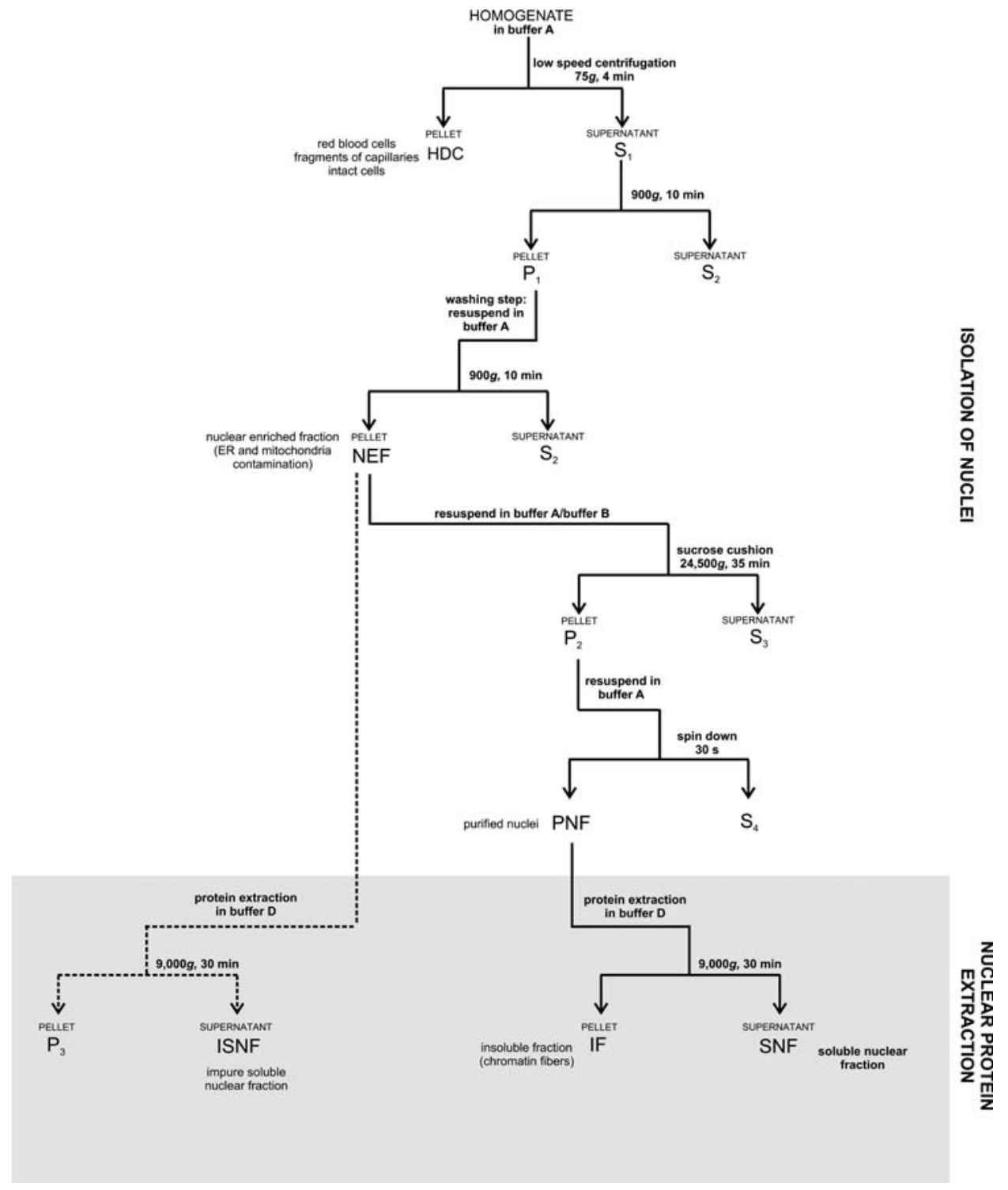

containing isolated nuclei is the PNF. PNF can either be processed immediately for protein extraction or be frozen and stored at $-80^{\circ} \mathrm{C}$.

\section{Nuclear Protein Extraction}

1. PNF was resuspended in $0.5 \mathrm{ml}$ of buffer $\mathrm{D}$ and incubated for $30 \mathrm{~min}$ with gentle rocking at $4{ }^{\circ} \mathrm{C}$.

2. Nuclei were completely lysed with ten passages through an 18-gauge needle.

3. Samples were centrifuged at $9,000 \mathrm{~g}$ for $30 \mathrm{~min}$ in a microcentrifuge.

4. The supernatant, the SNF, was aliquoted and stored at $-20^{\circ} \mathrm{C}$, while the insoluble fraction (IF) pellet was discarded.
Protein content of the SNF was assessed as described by Lowry [4].

\section{HIF-1 Induction}

The divalent metal salt cobalt chloride $\left(\mathrm{CoCl}_{2}\right)$, a known inducer of HIF-1 was used [5]. At embryonic day 11 eggs were windowed following a modification of the Hamburger procedure [6]. Briefly, a rectangular area of the shell roughly 4-6 $\mathrm{mm}^{2}$ in size was removed and the window was covered with Micropore tape ( $3 \mathrm{M}$ ). In embryonic day $12,1 \mathrm{~h}$ before sacrifice, the tapes were removed and $100 \mu \mathrm{l}$ of a $\mathrm{CoCl}_{2}$ solution or vehicle (saline) were applied to the vascularised chorioallantoic membrane. A concentration of $0.1 \mathrm{mM}$ of $\mathrm{CoCl}_{2}$ was used considering a final volume of $50 \mathrm{ml} / \mathrm{egg}$. 
The above protocol follows the Guide for the Care and use of Laboratory Animals from the Institute of Laboratory Animals Resources, Commission of Life Sciences, National Research Council, USA (NIH Publication No. 80-23, revised 1996). The number of animals used was minimized accordingly.

\section{Microscopy}

HDC, NEF, PNF and IF were fixed in cold $4 \%$ paraformaldehyde $\mathrm{w} / \mathrm{v}$ and $0.5 \% \mathrm{w} / \mathrm{v}$ glutaraldehyde dissolved in $0.1 \mathrm{M}$ phosphate buffer $(\mathrm{pH} 7.2-7.4)$ for $2 \mathrm{~h}$ at $4^{\circ} \mathrm{C}$. Each sample was then postfixed in the same buffer solution supplemented with $1 \% \mathrm{w} / \mathrm{v}$ osmium tetroxide. After two $15 \mathrm{~min}$ washes with distilled water, samples were immersed for $2 \mathrm{~h}$ in $5 \%$ (w/v) uranyl acetate and immediately dehydrated and embedded in a water-soluble aliphatic polyepoxide (Durcupan Fluka AG, Chemische Fabrik, Buschs SG, Switzerland).

For light microscopy analysis semithin $(1 \mu \mathrm{m})$, toluidine blue stained sections were photographed in a Zeiss Axiophot microscope equipped with a digital cooled camera.

For electron microscopy, ultrathin sections (70-90 nm) were contrasted with Reynolds' lead citrate [7] and then observed and photographed with a C10 Zeiss Electron Microscope.

For immunoelectron microscopy, PNFs were fixed as above but the embedment was in LR-White (London Resin Co. Hampshire, UK). Ultrathin sections were mounted on nickel grids and nonspecific binding sites were blocked by incubating the sections for $45 \mathrm{~min}$ on a drop of $0.2 \% \mathrm{BSA}$ and $0.1 \%$ Tween 20 in PBS at RT. After a short rinse in PBS, grids were incubated onto a drop of primary mouse anti-HIF-1 $\alpha$ (diluted 1/20) in a moist chamber at $4{ }^{\circ} \mathrm{C}$ overnight. After three short rinses in PBS, sections were incubated with secondary $10 \mathrm{~nm}$ gold-coupled goat antimouse antibody (Sigma-Aldrich Co. St. Louis, MO) diluted $1 / 50$ for $1 \mathrm{~h}$. The sections were then stained with uranyl acetate and lead citrate. Quantification of immunogold labelling was performed by a blinded investigator. The negative control, omitting the primary antibody, produced no labelling.

\section{Western Blotting}

Soluble nuclear fractions were denatured in loading buffer (62.5 mM Tris-HCl pH 6.8, 2\% SDS, $10 \% \quad \beta$-mercaptoethanol, $10 \%$ glycerol, $0.002 \%$ bromophenol blue) at $100^{\circ} \mathrm{C}$ for $10 \mathrm{~min}$ and then separated by electrophoresis on a SDS-polyacrylamide gel (Bio-Rad, Richmond, CA) at $10 \%$ for HIF- $1 \alpha$ and calnexin or $18 \%$ for histone $\mathrm{H} 3$ and cytochrome $c$. Proteins were then transferred to a PVDF membrane (Millipore Corporation, MA, USA). After blocking in $4 \%$ milk in phosphate-buffered saline with Tween 20 (T $0.05 \%$ in PBS $1 \times$ ) for $1 \mathrm{~h}$, membranes were incubated with the primary antibody overnight at $4{ }^{\circ} \mathrm{C}$ followed by HRP-conjugated secondary antibodies (Chemicon International, Inc., CA, USA). For primary antibodies the dilutions used were 1:1,000 for anti-HIF- $1 \alpha$, anticytochrome $c$ and anti-histone H3 monoclonal antibodies (Chemicon International, Inc., CA, USA) and 1:1,500 dilution for the anti-calnexin polyclonal antibody (a gift from J. Caramelo). A microsomal fraction and a pure mitochondrial fraction obtained from ED12 chick optic lobes [8] were, respectively, used as positive control for calnexin and cytochrome $c$.

Bands were detected by chemiluminescence using ECL Kit (Amersham Pharmacia Biotech). Optical density of the radioautograms was quantified with Gel-Pro Analyzer 3.1.

\section{Results}

The Low Speed Centrifugation Step Removes High Density Contaminants

Morphology assessment of HDC showed a large number of red blood cells (nucleated in avian species), fragments of capillaries and intact cells (Fig. 2a-b). In contrast, these high density contaminants were not found after the low speed centrifugation step in NEF and PNF (Fig. 2c-d).

\section{Density Sedimentation Step Removes ER and}

Mitochondrial Membranes from Nuclei

Electron microscopy analysis revealed that mitochondria and perinuclear membranes (fragments of ER) were detected in nuclei from NEF (Fig. 2c) but not observed after the density sedimentation step in PNF (Fig. 2d).

In order to further confirm the effectiveness of the density sedimentation step, two soluble protein extracts were compared. One of them was prepared with NEF and the other with PNF, yielding ISNF and SNF, respectively (Fig. 1). Those extracts reflect the protein content of pellets before and after the density sedimentation step. The purity of the soluble fractions was assessed by western blot using subcellular specific markers. Both fractions were positive for nuclear marker histone H3, but ISNF also had remarkable higher amounts of the ER marker calnexin and the mitochondrial marker cytochrome $c$ (Fig. 3).

\section{SDS Improves Protein Yield During the Extraction}

The effect of SDS low concentration on the protein extraction step was tested by comparing protein yield obtained with or without SDS in the extraction buffer 
Fig. 2 Morphologic analysis of the pellets. a Light micrograph of a representative sample of HDC containing significant amounts of high density contaminants: Red blood cells appearing as dark bodies (arrowheads), intact cells (asterisks) and fragments of capillaries (arrows) occasionally including a red blood cell. Only some of these components are indicated in the micrograph. Scale bar, $15 \mu \mathrm{m}$ (b-e) electron micrographs of the pellets. b HDC showing a red blood cell and intact cells. Scale bar, $500 \mathrm{~nm}$. c The nuclear enriched fraction, NEF, showing nuclei with perinuclear membrane contaminants and some mitochondria (arrows). Scale bar, $200 \mathrm{~nm}$. d Pure isolated nuclei in PNF. Scale bar, $250 \mathrm{~nm}$. e IF containing insoluble chromatin fibers after extensive extraction. Scale bar, $25 \mathrm{~nm}$

(A)

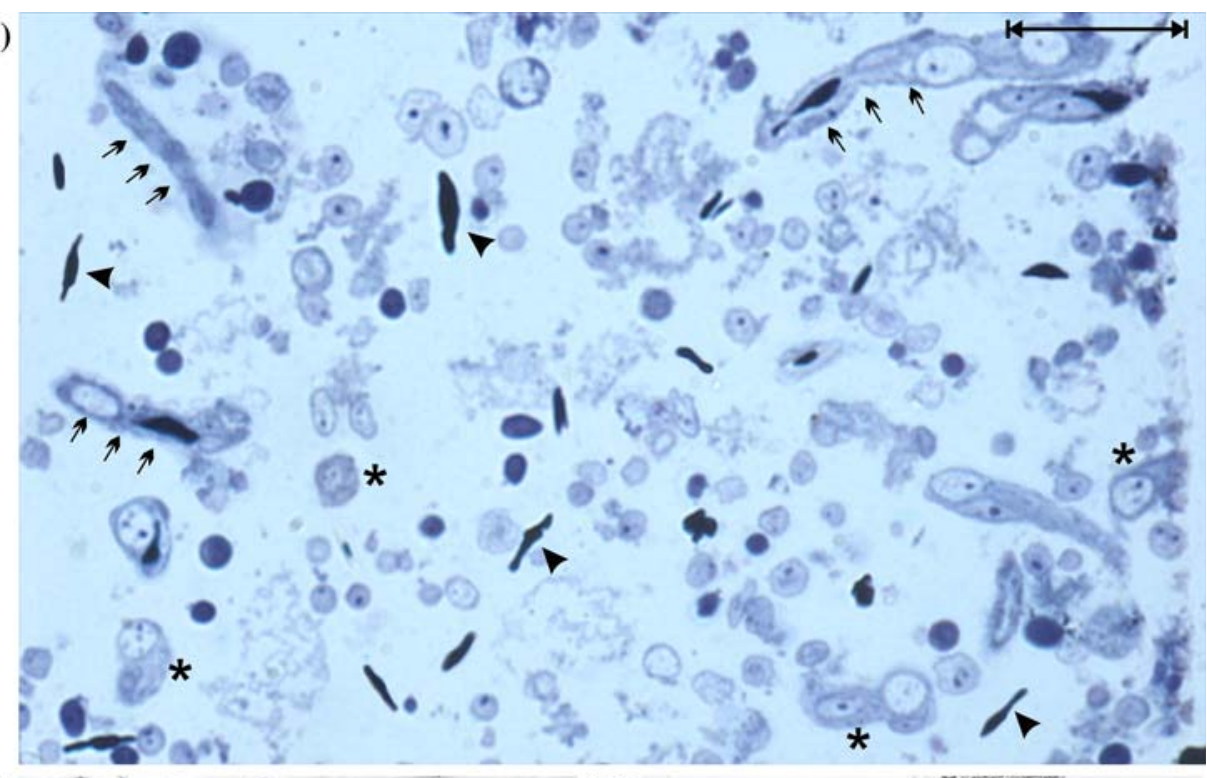

(B)

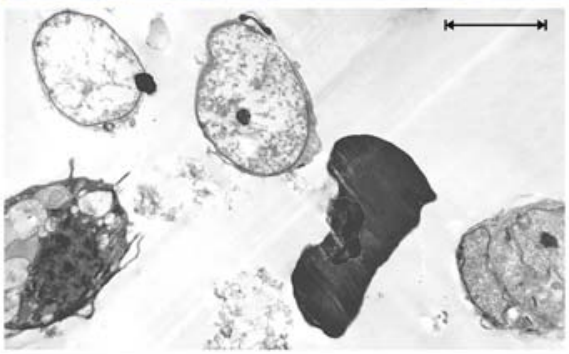

(D)

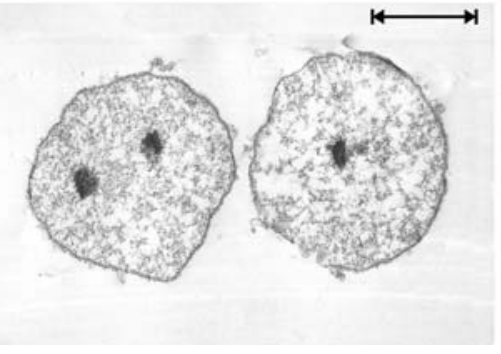

(C)

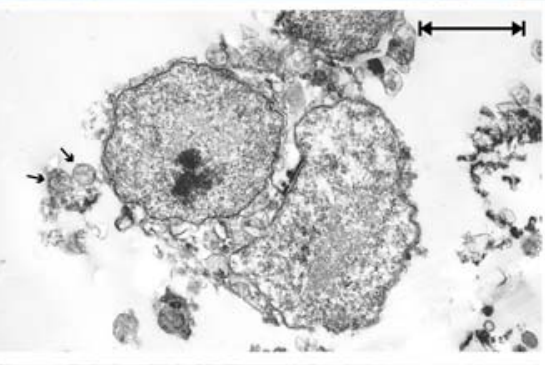

(E)

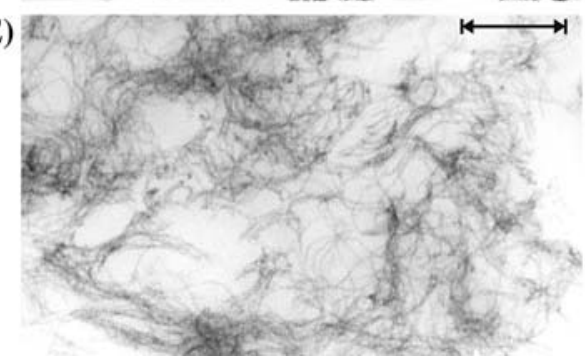

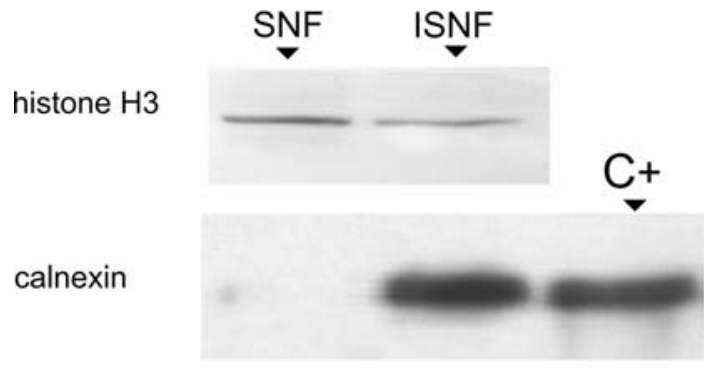

cytochrome c

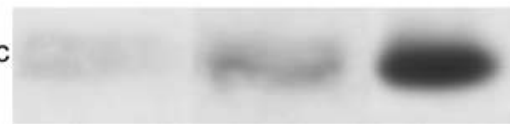

Fig. 3 Representative immunoblotting of SNF and ISNF revealed with subcellular specific antibodies: anti-histone $\mathrm{H} 3$ (nuclear), anticalnexin (ER) and cytochrome $c$ (mitochondrial). A microsomal fraction and a pure mitochondrial fraction were, respectively, used as positive controls $(\mathrm{C}+)$ for calnexin and cytochrome $c$ (buffer D). We found that protein extraction from PNF was improved by the use of a low concentration of SDS (Table 1). With this procedure protein extraction was extensive and IF had ultrastructural morphologies compatible with chromatin fibers (Fig. 2e). In order to avoid artifacts in the quantification, protein extracts obtained without SDS were added with the same amount of this detergent as the other samples before protein measurement. Composition of buffer D in "Experimental Procedures" reflects the SDS containing variant.

PNF and SFN are Suitable to Assess the Activation of Transcription Factors

To demonstrate that PNF and SFN obtained with the procedure described above were suitable to assess the activation of transcription factors in embryonic brain tissue, we 
Table 1 Effect of SDS on protein yield

\begin{tabular}{lll}
\hline & Protein yield (mg/g wet tissue) & Change $(\%)$ \\
\hline Without SDS & $1.18 \pm 0.12$ & - \\
With SDS & $1.49 \pm 0.17^{* *}$ & 26.3 \\
\hline
\end{tabular}

Nuclear protein extraction was performed with or without SDS in the extraction buffer (Buffer D). Values are means \pm SEM of $n=4$ independent experiments (** $P<0.01$, Student's $t$-test)

used the well-described induction of the transcription factor HIF-1 by $\mathrm{CoCl}_{2}$. This activation was determined by two different approaches. First, PNF was subjected to an immune-EM analysis. Quantification of gold particles revealed a significant increase in HIF- $1 \alpha$ levels after in vivo $\mathrm{CoCl}_{2}$ treatment compared to vehicle-treated embryos (Fig. 4). Second, HIF-1 $\alpha$ was detected by western blot of SNFs obtained from optic lobes of chick embryos. As expected, and in line with the immune-EM results, we found significantly increased HIF- $1 \alpha$ levels when $\mathrm{CoCl}_{2}$ was administered to the embryos $60 \mathrm{~min}$ before decapitation (Fig. 5).

\section{Discussion}

This paper describes modifications of the standard methods for obtaining a SNF from embryonic brain tissue. The main improvements of this procedure are: (1) the inclusion of a low speed centrifugation step to prevent the appearance high density contaminants such as red blood cells, fragments of capillaries and intact cells, (2) a modification of the Blobel and Potter [2] sucrose density gradient to remove ER and mitochondrial membranes and (3) a protein extraction approach based on shear stress, high salt and a combination of two classes of detergents, which enhances protein yield.
Morphological examination of HDC evidenced the importance of the low speed centrifugation as a key step to prevent the appearance of high density contaminants (Fig. 2a-b). The following step, the sucrose cushion, showed to be effective to remove perinuclear ER fragments and mitochondria, as electron microscopy of PNF revealed a preparation with little or no membrane contamination (Fig. 2d). In addition, western blot analysis of nuclear, ER and mitochondrial markers in SNF derived from PNF suggest that this step yields a purified sample (Fig. 3).

The density of the sucrose cushion is a critical parameter. If it is too low it will not remove contaminating membranes, while if it is too high it will not allow the pelleting of nuclei. In the original report [2], the density was set at $2.3 \mathrm{M}$ for adult rat liver preparations and different combinations of density steps to isolate nuclei are described in the literature. Many experimental procedures use a $2 \mathrm{M}$ sucrose cushion $[9,10]$. However, nuclei of several sources are not dense enough to pass through this cushion, resulting in poor yields of purified nuclei. Several reports have suggested that the appropriate sucrose step is tissue dependent $[11,12]$ but it has not yet been described for embryonic brain tissue. In this study, we found that a $1 \mathrm{M} / 1.6 \mathrm{M}$ density step was suitable for embryonic brain tissue. Furthermore, small increases above $1.6 \mathrm{M}$ led to a marked decrease of nuclear yield (data not shown).

Other experimental approaches for preparing nuclear extracts are based on the method of Dignam [13, 14] which consists of an extraction of proteins from a crude nuclear pellet with a high salt solution. Other studies use as nuclear extracts samples derived from a high salt extraction from a tissue homogenate [15] containing a significant contamination of cytoplasmatic components. Neither of these systems removes high density or perinuclear membranous contaminants.

The protein extraction step from purified nuclei used in this study takes advantage of the high salt extraction
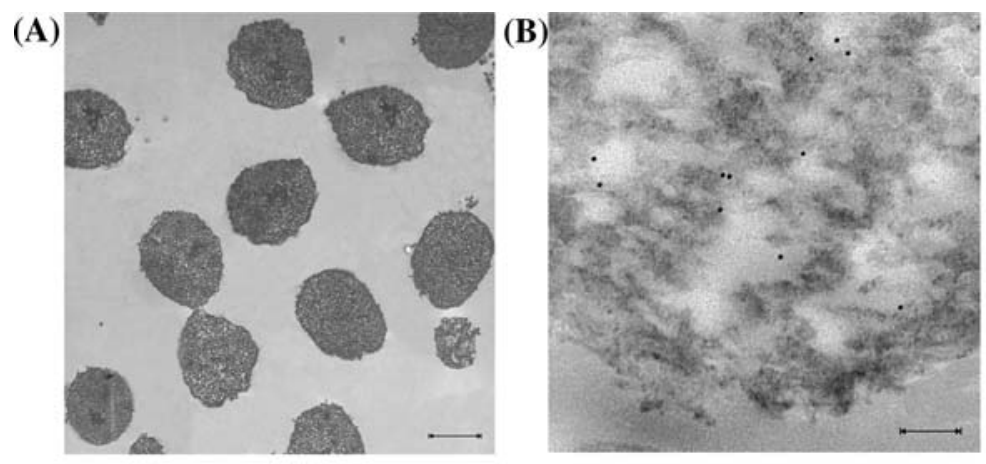
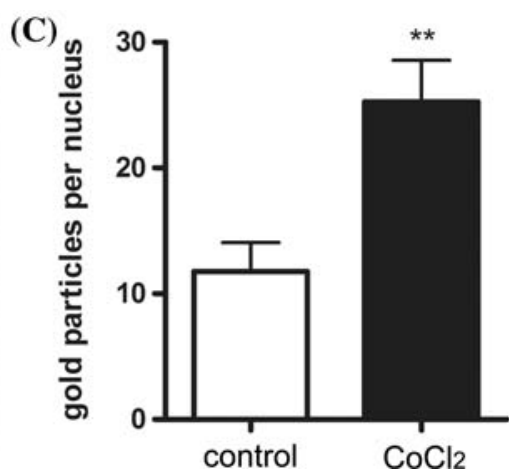

Fig. 4 Immunogold labelling of HIF-1 $\alpha$ using PNF. a Electron micrograph of a representative sample of PNF subjected to immunoEM analysis. Scale bar, $300 \mathrm{~nm}$. b Detail of a nucleus showing gold immunolabeling $(10 \mathrm{~nm})$ with antibodies specific for HIF-1 $\alpha$. Scale bar, $100 \mathrm{~nm}$. c Quantitative analysis showed significative differences between $\mathrm{CoCl}_{2}$ and control (vehicle-treated) embryos (** $P<0.01$, Student's $t$-test). 50 nuclei were analyzed in each condition 


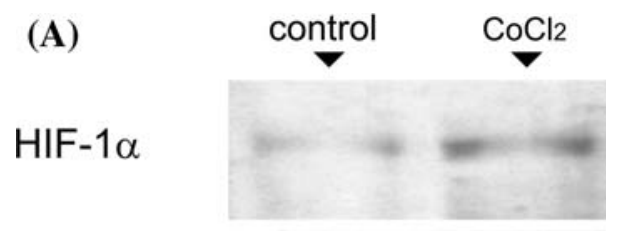

histone $\mathrm{H} 3$

(B)

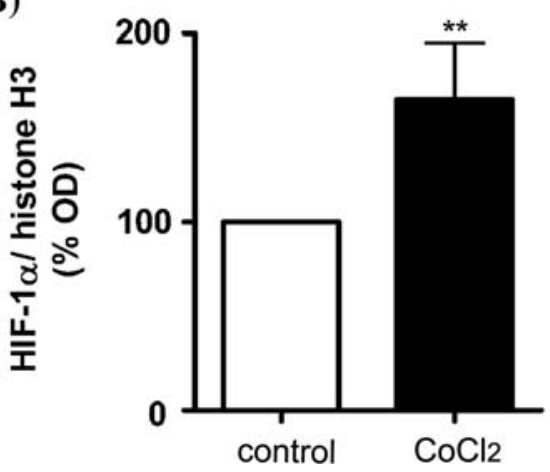

Fig. 5 a Representative immunobloting of SNF from control and $\mathrm{CoCl}_{2}$ treated animals revealed with anti-HIF-1 $\alpha$. Anti-histone H3 was used to confirm equal protein loading. b Densitometric analysis showed significative differences among treatments $(* * P<0.01$, Student's $t$-test). Optical density values are means \pm SEM of $n=4$ independent experiments

procedure to precipitate DNA. Detergents are also used in the extraction. Several studies have demonstrated that many proteins remain in the IF after nuclear protein extraction when non ionic detergents are used [16-18]. As mentioned above, an improvement of the method described here is the use of a low concentration of the ionic detergent SDS, which increased protein yield by $\sim 25 \%$ (Table 1) when compared to the use of the non ionic Triton-X-100 alone. The use of SDS does not interfere when SNF is subjected to electrophoresis, since in this technique the loading buffer typically contains SDS concentrations 80 times higher than that used in the extraction buffer.

The use of PNF and SNF from embryonic brain tissue in the study of transcription factors is demonstrated in this report using HIF-1 as an example (Figs. 4, 5). The transcription factor HIF-1 is a heterodimer composed of an $\mathrm{O}_{2}$-regulated HIF- $1 \alpha$ subunit and a constitutively expressed HIF-1 $\beta$ subunit [19] that has an essential role in the maintenance of oxygen homeostasis in metazoan organisms. $\mathrm{O}_{2}$-dependent degradation of HIF- $1 \alpha$ is triggered by the hydroxylation of specific proline residues by the prolyl hydroxylase PHD2 [20]. Under hypoxic conditions, PHD2 activity is reduced as a result of substrate limitation [21] leading to HIF- $1 \alpha$ accumulation. Then, HIF- $1 \alpha$ dimerizes with HIF-1 $\beta$, and together translocate to the nucleus, where they increase the transcription of target genes. It has been established that HIF- $1 \alpha$ accumulation can also result from the inhibition of the catalytic center of PHD2 (which contains $\mathrm{Fe}^{2+}$ ) by divalent metal cations such as $\mathrm{Co}^{2+}[5]$. Therefore, the accumulation of HIF- $1 \alpha$ in the nucleus is used as an indicator of HIF-1 induction, as in the present approach.

In conclusion, the procedure presently described appears to be reliable and convenient for obtaining of a pure SNF from a discrete amount of embryonic brain tissue. This fraction is suitable for the analysis of transcription factors by Western blot. Additionally, this protocol could be used to study developmental changes in nuclear protein content or modifications resulting from pharmacological or electrophysiological experiments.

Acknowledgments This research was supported by grants from National Research Council (PIP5410) and the National Agency for Promotion of Scientific and Technological Development (PICT 38234). We are very thankful to Dr. Jorge Caramelo for providing antisera against calnexin. The authors gratefully acknowledge Mrs. Lidia Margarita López for her expert technical assistance with the EM studies.

\section{References}

1. Morse RH (2007) Transcription factor access to promoter elements. J Cell Biochem 102:560-570

2. Blobel G, Potter VR (1966) Nuclei from rat liver: isolation method that combines purity with high yield. Science 154: 1662-1665

3. Cox B, Emili A (2006) Tissue subcellular fractionation and protein extraction for use in mass-spectrometry-based proteomics. Nat Protoc 1:1872-1878

4. Lowry OH, Rosebrough NJ, Farr AL et al (1951) Protein measurement with the Folin phenol reagent. J Biol Chem 193:265-275

5. Wang GL, Jiang BH, Rue EA et al (1995) Hypoxia-inducible factor 1 is a basic-helix-loop-helix-PAS heterodimer regulated by cellular O2 tension. Proc Natl Acad Sci USA 92:5510-5514

6. Hamburger V (1960) A manual of experimental embryology. The University of Chicago Press, Chicago, pp 143-149

7. Reynolds ES (1963) The use of lead citrate at high $\mathrm{pH}$ as an electron-opaque stain in electron microscopy. J Cell Biol 17:208212

8. Giusti S, Converso DP, Poderoso JJ et al (2008) Hypoxia induces complex I inhibition and ultrastructural damage by increasing mitochondrial nitric oxide in developing CNS. Eur J NeuroSci 27:123-131

9. Greenberg M, Bender IP (1997) Identification of newly transcribed RNA. In: Ausubel FM (ed) Current protocols in molecular biology. Wiley, New York

10. Farrell RE Jr (1998) Analysis of nuclear RNA. In: Farrell RE Jr (ed) A laboratory guide for isolation and characterization. Academic Press, San Diego, pp 406-437

11. Kim JS, Shukla SD (2006) Acute in vivo effect of ethanol (binge drinking) on histone $\mathrm{H} 3$ modifications in rat tissues. Alcohol Alcohol 41:126-132

12. Wheeler TT, Broadhurst MK, Rajan GH et al (1997) Differences in the abundance of nuclear proteins in the bovine mammary 
gland throughout the lactation and gestation cycles. J Dairy Sci 80:2011-2019

13. Dignam JD, Lebovitz RM, Roeder RG (1983) Accurate transcription initiation by RNA polymerase II in a soluble extract from isolated mammalian nuclei. Nucleic Acids Res 11:14751489

14. Helenius M, Hanninen M, Lehtinen SK et al (1996) Changes associated with aging and replicative senescence in the regulation of transcription factor nuclear factor-kappa B. Biochem J 318(Pt 2):603-608

15. Bergeron M, Gidday JM, Yu AY et al (2000) Role of hypoxiainducible factor- 1 in hypoxia-induced ischemic tolerance in neonatal rat brain. Ann Neurol 48:285-296

16. Biggs JR, Zhang Y, Peterson LF et al (2005) Phosphorylation of AML1/RUNX1 regulates its degradation and nuclear matrix association. Mol Cancer Res 3:391-401
17. Dechat T, Gotzmann J, Stockinger A et al (1998) Detergent-salt resistance of LAP2alpha in interphase nuclei and phosphorylation-dependent association with chromosomes early in nuclear assembly implies functions in nuclear structure dynamics. EMBO J 17:4887-4902

18. Kim TA, Lim J, Ota S et al (1998) NRP/B, a novel nuclear matrix protein, associates with $\mathrm{p} 110(\mathrm{RB})$ and is involved in neuronal differentiation. J Cell Biol 141:553-566

19. Semenza GL (2007) Life with oxygen. Science 318:62-64

20. Berra E, Benizri E, Ginouves A et al (2003) HIF prolylhydroxylase 2 is the key oxygen sensor setting low steady-state levels of HIF-1alpha in normoxia. EMBO J 22:4082-4090

21. Epstein AC, Gleadle JM, McNeill LA et al (2001) C. elegans EGL-9 and mammalian homologs define a family of dioxygenases that regulate HIF by prolyl hydroxylation. Cell 107:43-54 